\title{
Evaluating street cleaning operations for sustainability: the case of Osun State, Nigeria
}

\author{
S. A. Okanlawon, A. O. Afon, F. O. Adigun \& O. O. Odunola \\ Ladoke Akintola University of Technology, Ogbomoso, Nigeria
}

\begin{abstract}
This study evaluated street cleaning operations in Osun State, Nigeria. Data for the study were obtained from the street cleaners and residents through the administration of questionnaires. The study revealed that the cleaners were poorly paid, lacked job security and access to medical care, were poorly equipped and had no insurance policy cover. Waste generated from street cleaning operations was poorly managed; cleaners therefore adopted disposal methods that were not sanitary. Cleaners were exposed to hazards such as insect stings, offensive sights and odours, snakebites and automobile accidents. Residents perceived that the street cleaning operation had brought tremendous improvement to the sanitation conditions of selected roads; however, they were not ready to pay service charges. The study concluded that for the street cleaning operation to be sustainable, the working conditions of the cleaners and equipment provision must be substantially improved; and residents' perception of street cleaning operations as a social service changed.

Keywords: street cleaning, residents' satisfaction index, willingness to pay, waste disposal methods, hazards and risks, street cleaning equipment, street cleaners, residents' perception, environmental sanitation, sustainability.
\end{abstract}

\section{Introduction}

City environments, especially in developing nations, are characterized by a plethora of problems. Of importance among these problems is the unsanitary condition of the environment in which we work and live. Roads, as a city system, are not immune from the problem as they are littered [1]. Three types of negative impacts are associated with this poor environmental condition of roads, and according to Arafat et al [2], none of these impacts is easily quantifiable. First is 
the aesthetic blight and the second is medical. In order to avoid these two negative impacts, a street cleaning operation is usually embarked upon, which then makes the third impact insatiable. Thus, the third impact is the cost associated with street cleaning operations. Such a street cleaning operation was initiated by the Osun State Environmental Protection Agency (OSEPA), Nigeria.

Since the inception of the street cleaning operation, how sustainable it can be has not been scientifically investigated. This is considered to be of utmost importance so that it will not die naturally in the same way as similar exercises initiated in a different part of the country earlier on. Scientifically documenting the street cleaning operation can help other developing nations of the world to avoid pitfalls that can hinder sustainability.

To this end, this paper evaluated the street cleaning operations in the six urban areas used as experiments in Osun State, Nigeria. In particular, the study investigated the criteria for selecting street cleaners, the involvement of the local government in the exercise, job security, the cleaners' level of satisfaction and the urban residents' perception of the street cleaning operation.

\section{Literature survey}

Roads in the urban centres of Nigeria are in a bad physical condition, and in addition suffer from a poor environmental state [3]. Due to the poor solid waste management system in Nigerian cities [1], the street system has become a disposal site. Osun State is not unaffected by this practice. Similarly, the absence of a central sewer and waste water pit in individual houses has led to the roads being turned into the recipient of all of this waste [1]. Moreover, the keeping of animals and birds as free range [4] has added yet another component (animal dung, dead animals) among the waste to be cleared from Osun State roads. It is therefore evident that the street system is littered and is in a dirty condition.

Where streets are littered, three negative impacts are identified. According to Arafat et al [2], the first of these is the aesthetic blight. It is asserted that the more litter on roads, the uglier they are. The second impact is medical. It is recorded by Armstrong and Molyneux [5] that 5\% of all injuries at the Liverpool (England) hospital were caused by glass and that most of these occurred on roads. Similarly, the American College of Surgeons Committee on Control of Surgical Infections [6] reported that $15-27 \%$ of all lacerations recorded in urban emergency departments occurred from broken bottle glass while walking on streets. The bid to avoid the two negative impacts noted above results in the third: the cost associated with street cleaning. This third impact is inevitable where any street cleaning operation is put in place.

The composition of what is to be evacuated from roads and drainage varies considerably. Determining this are the residents and the residential characteristics of the areas in which the roads are located. These include the income, educational and social status of the residents $[2,7,8]$; the land use components [9], the effectiveness of waste management systems [10]; the availability of central sewer and wastewater pits and the existing legislation on environmental sanitation. The components of litter on roads include cigarette 
butts and condoms, syringes, fast food rubbish, broken bottles, paper, nylon and polythene materials, leaves, animal dung and dead animals and quite often, human biological waste $[2,4,11]$

It is important to note that in order to improve the sanitation condition of the environment in general, a road cleaning exercise is usually embarked upon. Participants in street cleaning exercises vary from one country to another. In the advanced countries of the world, garbage collection, especially in public spaces, is in private hands [12]. In such an arrangement, four stakeholders are identifiable - the regulatory agency, the cleaners, the private organization and the residents.

The equipment made available for the cleaners also varies. In the developed world street cleaning is modernized through the provision of water tanks and sprayers used to loosen particles and reduce dust. Mechanically propelled brooms are used to gather debris into a main collection area from which it is vacuumed and pumped into a collection bin [13]. Furthermore, it is suggested that gloves, protective shoes, uniforms and insurance cover should be provided for street cleaners in addition to job security [12]. The characteristics of this exercise have not been adequately documented in developing countries in general and in Nigeria in particular.

\section{Study area}

The study area is Osun, one of the 36 states in the Federal Republic of Nigeria. The poor environmental quality of the roads in the cities of Osun state necessitated the introduction of a street cleaning exercise by OSEPA. The exercise commenced in six zonal headquarters in 2004. The zonal headquarters are Ede, Osogbo, Ife, Ilesa, Iwo and Ikirun.

\section{Methodology}

The data for the study was collected through questionnaires administered in each of the six zonal headquarters. Two sets of questionnaires were completed.

The first set was completed by the cleaners. In selecting the cleaners for sampling, the registers containing their names were obtained from supervisors in each of the six centres. One out of every five cleaners was selected for sampling after the first cleaner had been randomly selected. Information obtained from the cleaners includes their socio-economic attributes; the materials available to work with and their general view of the exercise.

The second set of questionnaires was completed by the residents. Buildings from where residents were drawn for the survey were selected through systematic sampling techniques. The first building to be sampled along the streets where the cleaners were operating was randomly chosen. The subsequent unit of investigation was every 20th house. One person from each of the selected buildings was sampled.

Using the above methods, a total of 111 cleaners were surveyed. A breakdown of this figure revealed that $13,14,15,18,30$ and 21 cleaners were 
sampled respectively in Ile-Ife, Ikirun, Iwo, Ilesa, Ede and Osogbo. Similarly, 12, 14, 22, 24, 15 and 14 residents were sampled in Ile-Ife, Ikirun, Iwo, Ilesa, Ede and Osogbo respectively. In essence, 101 residents were sampled in the six towns. The data obtained were analyzed through descriptive statistics.

\section{Research findings}

The findings of the study are as presented in the sections below. All tables in this section emanated from the field survey of January 2008.

\subsection{The attributes of the street cleaners}

Of the 111 street cleaners sampled, $79(71.2 \%)$ were female. The rest of the 22 $(28.8 \%)$ were male. This was an indication that the exercise was attractive to the female gender. The proportion of young adults (31-55 years) was high among the cleaners. This age bracket represented $58.6 \%$ of the cleaners. The remaining 46 $(41.4 \%)$ cleaners were youths (18-30 years). The cleaners were low in educational status. The proportion with no formal education was $16.2 \%$ while $19.8 \%$ had a primary school educational. The highest proportion of the street cleaners had a secondary school education $(57.7 \%)$ and only $6.3 \%$ claimed they had been to a tertiary institution.

All of the cleaners were on a flat monthly stipend of Five Thousand Naira $(\mathrm{N} 5,000.00)$. Note that $\mathrm{N} 117: 00=\$ 1.00$. The study further established that $69.4 \%$ of the cleaners were employed in $2005 ; 16.2 \%$ in 2006 while $11.8 \%$ and $2.7 \%$ were respectively employed by OSEPA in 2007 and 2008 . Investigation also showed that $20.7 \%$ of these cleaners would continue to stay in job as long as they were allowed. The remaining $88(79.3 \%)$ would discontinue the job as soon as they secured more gainful employment. Other characteristics of the job include: the job is not pensionable, the cleaners can be sacked any time, and indeed, the cleaners need not give notice to disengage from the exercise. The cleaners were not entitled to insurance cover, leave allowance, free medical care for themselves and their dependant relatives or annual leave.

The cleaners made it known that they operated only on selected roads. The criteria for selecting roads were not specified; except that the roads on which cleaners were working are the major ones. The road length to be cleaned daily is left to the discretion of the zonal supervisor. The cleaners worked daily between the hours of 8.00 a.m. and 2.00 p.m. The cleaners usually worked only during the working days of the week. However, $11.7 \%$ of the cleaners indicated they had had cause to work occasionally on Saturday under special arrangement.

Of importance in the operations of the street cleaners is the equipment supplied by OSEPA. The cleaners can be identified at work through the uniform supplied to all. One of the major tools they worked with is the local broom. This was usually supplied once at the initial stage of employment. However, the cleaners usually met subsequent needs for this tool themselves. Of the surveyed cleaners, only $9.9 \%$ were supplied with protective shoes. The local basket was supplied to $48.6 \%$; nose protectors, hand gloves and disinfectant were supplied respectively to only $20.7 \%, 48.6 \%$ and $5.6 \%$ of the cleaners. 
The cleaners were to sweep the roads and clean the drains. No concrete means of collecting, transporting and disposing of waste generated from the exercise was put in place by the OSEPA. As a result, the cleaners employed different methods of disposing of the waste they generated. Presented in Table 1 is the different means of disposing waste.

Table 1: The different methods of disposing of waste generated from the road cleaning exercise.

\begin{tabular}{|l|c|c|}
\hline Waste disposed method & No of responses & $\begin{array}{c}\text { Proportion of } \\
\text { the method }\end{array}$ \\
\hline Burning & 35 & 10.0 \\
\hline Local government refuse van & 67 & 19.2 \\
\hline Dumping inside the drain & 39 & 11.2 \\
\hline Wheel barrow operated by cleaners & 57 & 16.2 \\
\hline Packed inside sacks & 36 & 10.3 \\
\hline Dumped on available open space & 11 & 3.2 \\
\hline River banks & 39 & 11.2 \\
\hline Road set back & 26 & 7.4 \\
\hline Left to decay & 39 & 11.2 \\
\hline Total & $349^{* *}$ & 100.0 \\
\hline
\end{tabular}

** Note: The responses exceeded the number of cleaners surveyed because of multiple responses.

The most important means of disposing was through the local government refuse van. It accounted for $19.2 \%$ of all the various methods. It was established however, that it was not mandatory for the local government refuse van to collect the waste daily. Second in importance was the use of a wheelbarrow that can be operated by any of the cleaners. This method represented $16.3 \%$ of the methods. The problem with these means, except through the local government refuse van, was that the waste collected would be dumped close to where it was generated.

The hazards that cleaners had actually experienced during their operations were investigated. It was established that cleaners were prone to more than one hazard. Summarized in Table 2 is the number of cleaners that had actually experienced each of the identified hazards and the proportion that each represented relative to all the hazards. It can be deduced from Table 2 that all of the cleaners had suffered from offensive sights emanating from the poor environmental sanitation habits of the residents, such as defecating inside drains to be cleaned. This represented $25.1 \%$ of all hazards that they had actually experienced. Second in rank is exposure to offensive odours. Ninety-six cleaners had actually experienced this; however, it represented $21.7 \%$ of the hazards. Other hazards that cleaners were exposed to included insect stings (14.3\%); contracting colds, catarrh and coughs from dust $(20.0 \%)$ and wounds from sharp objects $(12.7 \%)$. It was discovered that cleaners involved in automobile accidents during operations were usually responsible for the medical bill. 
Table 2: $\quad$ Hazards actually experienced by cleaners.

\begin{tabular}{|l|c|c|}
\hline Hazard & $\begin{array}{c}\text { Cleaners that } \\
\text { had actually } \\
\text { been involved }\end{array}$ & $\begin{array}{c}\text { Proportion of } \\
\text { the hazard }\end{array}$ \\
\hline Insect string & 63 & 14.3 \\
\hline Snake bite & 8 & 1.8 \\
\hline Wounds from sharp object & 56 & 12.7 \\
\hline Automobile accident & 15 & 3.4 \\
\hline Exposure to offensive odour & 96 & $21 / 7$ \\
\hline Exposure to offensive sight & 111 & 25.1 \\
\hline $\begin{array}{l}\text { Catching cold, catarrh and cough } \\
\text { from dust }\end{array}$ & 93 & 20.0 \\
\hline Total & $442 * *$ & 100.00 \\
\hline
\end{tabular}

** Note: The responses exceeded the number of cleaners surveyed because of multiple responses.

Cleaners were instructed to rate how satisfied they are with each of the identified aspects of their operations. Five ratings were provided. These ratings are 'very much satisfied', 'satisfied', 'just satisfied', 'not satisfied' and 'not at all satisfied'. From the information supplied, a satisfaction index was computed for each aspect. In the computation of the index, a value of 5, 4, 3, 2 and 1 is respectively assigned to the above ratings. Therefore, the index to each aspect will be between 5 and 1. How the index is computed can be obtained from Afon [14]. The nearer the index to 5, the higher the satisfaction derived from such an aspect of the job. The satisfaction index of the income, the length of time spent daily on the work, the health hazard involved, the politeness of OSEPA workers, the politeness of the residents, the regularity of payment and the quantity and quality of working tools supplied were respectively 1.6, 2.6, 1.6, 1.8, 1.8, 2.5, 1.8 and 1.6. The overall satisfaction level of the cleaners on the job was computed as 1.8. Therefore, income from the job, health hazards involved and the quantity and quality of the tools supplied had an index that was lower than the overall average satisfaction index. It can be concluded that the cleaners were generally not satisfied with the job. The overall index of 1.8 implied that the satisfaction derived from the work was less than average as the satisfaction fell between 'not satisfied' and 'not at all satisfied'.

\subsection{Residents' perception of the street cleaning exercise}

This section examines the views of residents on the exercise. First to be considered is the level of awareness of the exercise. It was found that $83(82.2 \%)$ of the residents were aware that the street cleaning exercise was going in their areas. Residents recognized the cleaners through their uniform and the broom and rake with which they perform their duties. They were also aware that the cleaners usually worked from Monday through to Friday. The residents also submitted that cleaners resume for duty in the morning; however, the departure time was not known. 
It was established that $60.4 \%, 14.3 \%, 9.9 \%, 12.1 \%$ and $3.3 \%$ of the residents observed that waste generated was removed respectively daily, every other day, weekly, occasionally and not removed at all. The probability therefore that waste generated was removed on a daily basis was thus very high. Similarly, $33 \%$ of the residents believed that the waste generated was usually burnt.

Despite the poor equipment used by the cleaners, and the occasional burning and dumping into drains of waste recovered, $78 \%$ of the residents were of the opinion that the road conditions had improved tremendously since the inception of the exercise. Indeed, $92.3 \%$ of the residents supported the continuous existence of the exercise. However, this should be at no extra cost to the residents. This was because only $5.5 \%$ of the residents would support payment for this service.

\section{Conclusion}

The findings of this study raise implications for the sustainability of street cleaning exercise in Osun State, Nigeria. In the first place, the cleaners' income of $\$ 1.42$ dollars per day was not commensurate with the hazards and risks associated with the service rendered. That the cleaners had no job security and the satisfaction derived from the various aspects of their operations was very low are good reasons to note that they were not putting in their best. Similarly, that the cleaners can leave the job very easily was also not healthy for the sustainability of the exercise.

The equipment provided by OSEPA for the cleaners to work with was not adequate. Similarly, no sustainable plan was in place to make sure that waste generated from the exercise was collected on a daily basis. The reliance on the local government refuse van that occasionally came for collection was not a good plan, especially as no relationship between the local government and OSEPA on this exercise existed. It was therefore not mandatory for a local government refuse van to collect waste; rather, it was obligatory. Moreover, that the residents were not paying both for the waste collection service of the local government and for street cleaning exercise indicated that the latter, like the former, may not be sustainable. Indeed, this study indicated that residents were not prepared to pay for the exercise, yet they wanted the exercise to continue. It was observed by the authors that the street cleaning exercise was put in place as a poverty alleviation program rather than a commitment to keep the street systems in particular, and the urban environment in selected cities of Osun State, in general conditions conducive to human healthy living on a sustainable basis. Our fear is that there may not be a legal basis for the continuation of the exercise after the regime of the present governor, as experience has shown that one of the major problems confronting sustainability of many projects and exercises in Nigeria is the lack of continuity. Another important implication of the findings was that no adequate provision was made for how to dispose of waste generated from the exercise. The exercise was therefore, in the authors' observations, adding to the existing problems of poor waste management system in these selected cities. 
Therefore, for the street cleaning exercise to be sustainable, it is imperative that:

a) The street cleaners, who are the major stakeholders in the exercise, should be paid a living wage. There should be job security for them. Indeed, they should be insured against hazards emerging from their occupation.

b) Adequate provision should be made for modern equipment. Mechanical cleaners should be purchased and utilized. The exercise should not be conceived as a poverty alleviation program any longer. Legislation should be put in place to back the exercise for continuity.

c) As advocated earlier, residents should pay a service charge for sustainability [1]. It is high time the conception of environmental sanitation services as social services is revisited. Earlier findings that residents' willingness to pay for environmental sanitation charges is high, on the condition that the service quality is high, is an advantage for charging fees [15]. The challenge is, however, in the government improving the service quality. If street cleaning exercises are to be sustainable, they must be sustained from service charges collected, otherwise they will die a natural death.

d) There is the need to foster a legal relationship between the agency monitoring the exercise (OSEPA) and the local government department of water and environmental services. We are of the opinion that the function of collecting, transporting and disposing of waste emanating from street cleaning exercises should be made mandatory for the local government, while the state will continue to make financial subventions available to complement the amount realized from service charges.

e) Efforts should be made to privatize the exercise. This will involve the enactment of enabling legislation. In such a situation, the OSEPA will be putting in place an environment enabling the exercise to be financially sustainable through the stipulation of what private operators can collect as service charges. The present situation of the government controlling every aspect of the exercise (the purchase of equipment, operations and the payment of salaries) cannot be sustainable, especially now that there are high fraudulent and corruption practices in government services. While the exercise was a welcome development, it is observed that it may not be sustainable unless the suggestions in this work are implemented.

\section{References}

[1] Afon, A. O, Solid Waste Management in selected cities of Oyo State, Nigeria. Ph.D dissertation submitted to department of Urban and Regional Planning, Obafemi Awolowo University, Ile-Ife, Nigeria; 2005.

[2] Arafat, H. A. Al-Khatib, I. A., Daoud, R. and Shwahrel H., Influence of Socio-economic factors on street litter generation in the Middle East: the 
effects of educational level, age, and type of residence. Waste Management and Research, 25 (4) pp 363-370, 2007.

[3] Fadare, S. O. and Wojuade, C. A., Study of Traffic delay situation in Ibadan, Nigeria. Ife Planning Journal, 3 (1) pp 1-15, 2007.

[4] Afon, A. O. and Okewole I. A. Estimating the Quantity of Solid Waste Generation in Oyo, Nigeria. Waste Management and Research, 25 (4) pp 371-379, 2007.

[5] Armstrong, A. M and Molyneux, E. Glass Injuries to Children. British Medical Journal 340: pp 360-365, 1992.

[6] American College of Surgeon Committee on Control of Surgical Operations, Control of Infections in Surgical Patients $2^{\text {nd }}$ Editions, JB Lippin Cott, Philadelphia, PA, 1984.

[7] Ban Benkering, P. Sehker, M. Garlagh, R. and Kumer, V. Analyzing Urban Solid Waste in Developing Countries: a perspective in Bangalore, India, Working Paper, No. 24, 1999.

[8] Afon Abel, An Analysis of Solid Waste Generation in a Traditional African City: The Example of Ogbomoso, Nigeria. Environment and Urbanization 19(2), pp 527-538, 2007.

[9] Rusbrook, P and Pough, M., Solid Waste and Landfills in Middle and Low Income Countries. World Bank Technical Paper No. 426, 1999.

[10] Faniran, G., Spatial Pattern of Solid Waste Disposal along the Lagos Ibadan Express road, Ibadan, Nigeria. B.Sc. dissertation, Department of Urban and Regional Planning, Obafemi Awolowo University, Ile-Ife, Nigeria, 2008.

[11] New South Wales Environmental Protection Agency, Government Litter Prevention Program. http://www.epa.nsw.govau/litter/program.htm.

[12] Busck, O, Marketisation of refuse Collection in Denmark: Social and Environmental Quality Jeopardized. Waste Management and Research, 25 (4) pp 384-391, 2007.

[13] Wikipedia Encyclopedia, Street sweeper. www:http:patft.uspto.gov, 2008.

[14] Afon, A.O., Informal sector initiative in the primary sub-system of urban solid waste management in Lagos, Nigeria. Habitat International, 31, pp.193-204.

[15] Afon, A.O., An evaluation of residents' willingness and affordability to pay for solid waste management in Asaba, Delta state, Nigeria. Ife Planning Journal, 3(1), pp.39-50, 2007. 